\title{
Interfaces in Next Generation Ta and NbO Solid Electrolytic Capacitors
}

\author{
Matthew Olszta, Jennifer Sloppy, Jinguo Wang, Elizabeth C. Dickey* \\ *The Materials Research Institute (MRI), the Pennsylvania State University, University Park, PA \\ 16802
}

On the forefront of capacitor technology sit solid electrolytic capacitors, which are high capacitance capacitors produced from powders of valve metals (e.g., Ta, Nb) or valve metal oxides (e.g., NbO). By utilizing the high $\mathrm{CV} / \mathrm{g}$ of these materials, smaller capacitors (e.g., surface mount devices) can be produced to accommodate the electronics industries push towards miniaturization, such as for use in cell phones and laptops. The increased charge and miniaturization are achieved by sintering these powders and subsequently anodizing the sintered body to create one half of a capacitor. The thickness of the dielectric layer, and thus the capacitance, is dependent upon the anodization voltage. To complete the metal-insulator-semiconductor structure, a manganese oxide $\left(\mathrm{MnO}_{2}\right)$ or conductive polymer layer is then coated onto the newly formed dielectric layer. Unfortunately, as the dimensions decrease towards the nanoscale, new problems begin to arise from size effects (e.g., cracking of the oxide at grain boundaries). In addition to physical flaws, there are numerous conductive, amorphous intermediate oxides, which can diminish the capacitance of the part. Lastly, the dielectric oxide can also crystallize and become conductive, which leads to current leakage.

Using high-resolution transmission electron microscopy (HRTEM), we can determine the structural characteristics of the three-component capacitor system. The metal-oxide interfaces of both the Ta$\mathrm{Ta}_{2} \mathrm{O}_{5}$ (Fig. 1A) and the $\mathrm{NbO}-\mathrm{Nb}_{2} \mathrm{O}_{5}$ (Fig. 1B) capacitors have sharp transitions, which is desired in producing high-quality capacitors. The coverage of the cathode on the opposite surface of the dielectric is equally important for good capacitance. As seen in Figure 2, the difference between the $\mathrm{MnO}_{2}$ and polymer at the $\mathrm{Ta}_{2} \mathrm{O}_{5}$ interface can clearly be seen, as the polymer/dielectric interface (Fig. 2A) is much sharper than the $\mathrm{MnO}_{2} /$ dielectric interface (Fig. 2B). Yet, both of these interfaces have greater contact than that observed at the $\mathrm{MnO}_{2} / \mathrm{Nb}_{2} \mathrm{O}_{5}$ interface (Fig. 2C), which appears to have many gaps. Lastly, the amorphous dielectric can crystallize due to a buildup of heat within the part, thereby providing a path for current, which will diminish the capacitance. Using HRTEM, we can identify these nucleation and crystallization events to get a better understanding of where they occur.

Both $\mathrm{Ta}$ and $\mathrm{Nb}$ are considered valve metals, in which the amorphous pentoxides have dielectric properties. As previously mentioned, during formation there can be other amorphous sub-oxides formed between the anode and the pentoxide, which are conductive, thereby lowering the dielectric thickness of the part. HRTEM cannot be utilized to distinguish between these the conductive suboxides and dielectric pentoxide, therefore in order to detect the presence of these intermediates, we have used electron energy loss spectroscopy (EELS) to map the chemical gradients across the dielectric layers (Fig 3). The chemical spectra for the various suboxides will allow us to determine their location and thickness at the anode boundary, thereby providing a better understanding of how/why parts fail. 

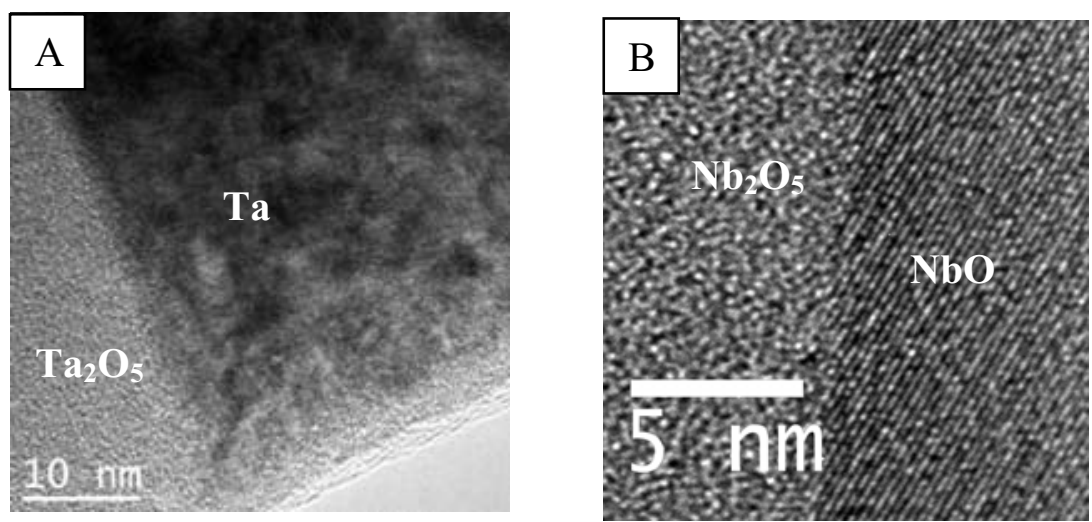

Figure 1: High-resolution TEM micrographs of anode-dielectric interface of $\mathrm{Ta}$ and $\mathrm{NbO}$ capacitors. A) $\mathrm{Metal} /$ ceramic $\mathrm{Ta} / \mathrm{Ta}_{2} \mathrm{O}_{5}$ interface which illustrates a distinct transition. B) Ceramic/ceramic $\mathrm{NbO} / \mathrm{Nb}_{2} \mathrm{O}_{5}$ interface also showing a distinct boundary between the anode and dielectric.
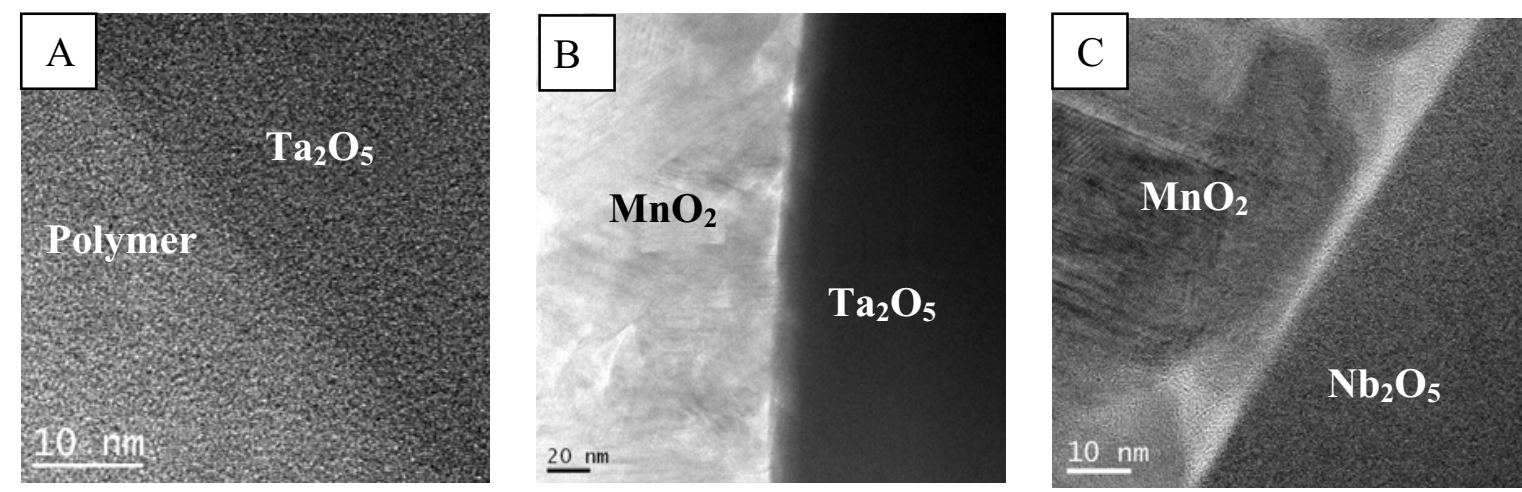

Figure 2: High-resolution TEM micrographs of the dielectric-cathode interfaces of Ta/polymer, $\mathrm{Ta} / \mathrm{MnO}_{2}$ and $\mathrm{NbO} / \mathrm{MnO}_{2}$ capacitors. A) $\mathrm{Ta}_{2} \mathrm{O}_{5} /$ conductive polymer interface, which shows a sharp boundary between the two materials. B) $\mathrm{Ta}_{2} \mathrm{O}_{5} / \mathrm{MnO}_{2}$ interface illustrating slightly porous nature of boundary. C) $\mathrm{Nb}_{2} \mathrm{O}_{5} / \mathrm{MnO}_{2}$ interface which shows porosity between the $\mathrm{Nb}_{2} \mathrm{O}_{5}$ and $\mathrm{MnO}_{2}$.

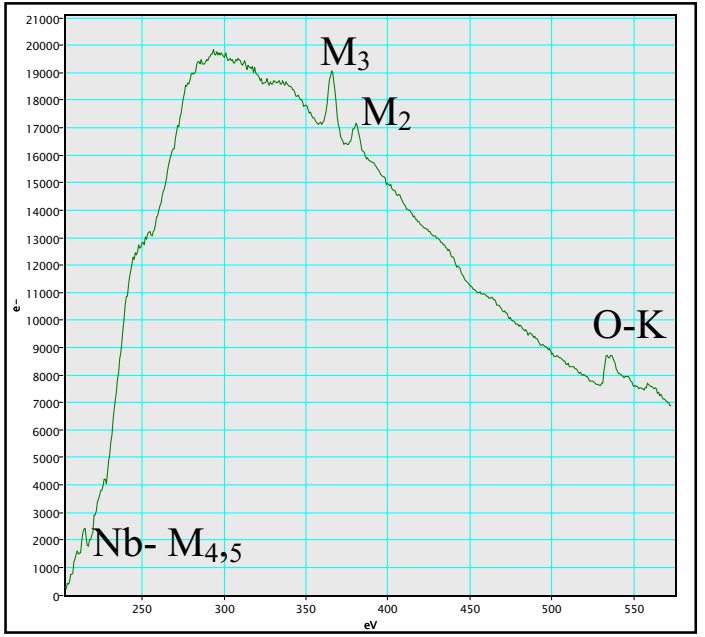

Figure 3: Electron energy loss spectrum of amorphous $\mathrm{Nb}_{2} \mathrm{O}_{5}$ showing the $\mathrm{Nb}-\mathrm{M}_{4,5} \mathrm{M}_{3}$ and $\mathrm{M}_{2}$ edges, as well as the $\mathrm{O}-\mathrm{K}$ edge. 